\title{
Has there been an information explosion in histopathology?
}

\author{
S S Cross, F Macgillivray
}

\begin{abstract}
The numbers of papers published between 1966 and 1990 which could be of relevance to a histopathologist were assessed. The search for papers was conducted under 18 medical subject headings using the CDPlus Medline computerised database for the years 1966, 1978, 1982, 1986 and 1990. Between 1966 and 199016 categories showed an increase in the number of indexed papers and in 11 of these the increase was by over $200 \%$. The two categories that showed a slight reduction were cytodiagnosis and polarisation microscopy. The total number of papers of probable relevance to histopathology in 1990 was 36780 , a $293 \%$ increase since 1966; this increase was greater than the increase in the total number of papers indexed $(189 \%)$.

The number of papers relevant to histopathology has increased dramatically in recent years and this increase has been proportionately greater than in some other areas of medicine.
\end{abstract}

A histopathologist needs to be aware of new developments which influence the practice of diagnostic surgical pathology and necropsy work. Some of this new information may be acquired by attending courses or conferences but most is obtained by reading pathology journals. The amount that a histopathologist needs to read must be taken into account when assessing workloads and allocation of time to different activities during the working week.

The earliest surviving scientific journal was published in 1665 and the number has been steadily increasing since then. ${ }^{1}$ By 1964 it was estimated that at a reading rate of two papers a day it would take 27.4 centuries to read all the biomedical journals published in that year, ${ }^{2}$ and de Solla Price estimated that the doubling time of the world scientific literature was 10-15 years. ${ }^{3}$ This increase in the amount of published data has been termed the information explosion. ${ }^{4}$ The proliferation of journals in medical specialties has not been extensively studied; one report has considered the increase in radiology journals ${ }^{4}$ but to our knowledge there has been no report of the phenomenon in histopathology.

Computerised literature databases allow searches to be made more quickly and more objectively than manual searches of printed listings of published papers. ${ }^{5}$ This study uses a computerised literature database to investigate whether there has been an information explosion in histopathological journals.

\section{Methods}

Searches were carried out on the CD-Plus system (CD Plus Inc, 333 Seventh Avenue, 6th Floor, New York, NY 10001, USA) which utilises information encoded on compact discs in a read-only form (CD-ROM). The Medline database was used which includes papers listed in Index Medicus, the Index to Dental Literature, and the International Nursing Index. The searches were restricted to papers published in English and those dealing with human pathology. The number of papers published in various categories was recorded for the years $1966,1978,1982,1986$ and 1990 . The categories were selected from the medical subject headings listed in Index Medicus. ${ }^{6}$ The categories were chosen from two major headings, El-procedures and techniques-diagnostic, and E5-procedures and techniques-miscellaneous. The minor headings within these groups were selected if they were assessed to be relevant to the practise of histopathology. Eighteen categories were examined (tables 1 and 2).

The years between 1966 and 1978 were excluded from the study because during this period there were major changes in the policies for selecting papers to be included under specific medical subject heading categories. An example of this is the policy for the medical subject heading "autopsy" (E5.70). The current instructions to indexers for autopsy permit inclusion of articles discussing it as a procedure but not as a "routine coordinate" for postmortem pathology. In the period around 1970 and 1974 any paper with necropsy findings in it (such as a case report) could have been included in the category and this led to an artefactual (for the purposes of this study) increase in the number of papers under this heading.

The total number of papers in 1966 and 1990 which could be relevant to a histopathologist was calculated by adding up all categories except the broader categories ("diagnosis, laboratory" (E1.223); "technology, medical" (E5.909)) and the number under subheadings being subtracted from the main headings-for example, "vaginal smears" (E1.223.230.730) was subtracted from "cytodiagnosis" (E1.223.230) before addition.

Results

The results are given in tables 1 and 2 . The 
Table 1 Categories within medical subject heading E5-procedures and techniques: miscellaneous

\begin{tabular}{lrrrrr}
\hline Year & 1966 & 1978 & 1982 & 1986 & 1990 \\
\hline Autopsy & 130 & 502 & 329 & 352 & 351 \\
$\quad$ E5.70. & 4293 & 3742 & 7078 & 8256 & 6945 \\
$\begin{array}{l}\text { Microscopy } \\
\text { E5.595. }\end{array}$ & 3020 & 3323 & 6424 & 7579 & 6132 \\
$\begin{array}{l}\text { Microscopy, electron } \\
\text { E5.595.346 }\end{array}$ & 344 & 221 & 400 & 427 & 595 \\
$\begin{array}{l}\text { Microscopy, fluorescence } \\
\quad \text { E5.595.458 }\end{array}$ & 49 & 23 & 32 & 42 & 29 \\
$\begin{array}{l}\text { Microscopy, polarisation } \\
\quad \text { E5.595.624 }\end{array}$ & 6394 & 8871 & 10820 & 13374 & 16400 \\
$\begin{array}{l}\text { Technology, medical } \\
\quad \text { E5.909 }\end{array}$ & 2624 & 4929 & 6293 & 8732 & 11637 \\
$\begin{array}{l}\text { Cytological techniques } \\
\text { E5.909.262 }\end{array}$ & 1688 & 1308 & 1461 & 2731 & 5007 \\
$\begin{array}{l}\text { Histocytochemistry } \\
\text { E5.909.262.607 }\end{array}$ & $\star$ & $\star$ & 3 & 20 & 4058 \\
$\begin{array}{l}\text { Immunohistochemistry } \\
\text { E5.909.262.607.512 }\end{array}$ & 2909 & 2317 & 2741 & 4455 & 6601 \\
$\begin{array}{l}\text { Histological techniques } \\
\text { E5.909.432 }\end{array}$ & & & & & \\
\hline
\end{tabular}

Table 2 Categories within medical subject heading E1-procedures and techniques: diagnostic

\begin{tabular}{|c|c|c|c|c|c|}
\hline Year & 1966 & 1978 & 1982 & 1986 & 1990 \\
\hline $\begin{array}{l}\text { Diagnosis, laboratory } \\
\text { E1 } 1.223\end{array}$ & 11364 & 15987 & 19901 & 24248 & 27596 \\
\hline $\begin{array}{l}\text { Biopsy } \\
\text { E1.223.88 }\end{array}$ & 1017 & 1057 & 1574 & 1939 & 2249 \\
\hline $\begin{array}{r}\text { Cytodiagnosis } \\
\text { E1.223.230 }\end{array}$ & 535 & 443 & 385 & 448 & 413 \\
\hline $\begin{array}{l}\text { Vaginal smears } \\
\text { E1.223.230.730 }\end{array}$ & 239 & 194 & 162 & 232 & 265 \\
\hline $\begin{array}{l}\text { Specimen handling } \\
\text { E1.223.894 }\end{array}$ & 1563 & 2506 & 3171 & 3771 & 4526 \\
\hline $\begin{array}{l}\text { Biopsy } \\
\text { E1.233.894.143 }\end{array}$ & 1017 & 1448 & 2085 & 2627 & 3216 \\
\hline $\begin{array}{l}\text { Biopsy, needle } \\
\text { E1.223.894.143.310 }\end{array}$ & $\star$ & 409 & 527 & 712 & 859 \\
\hline $\begin{array}{l}\text { Total number of papers indexed on } \\
\text { Medline }\end{array}$ & 175513 & 255934 & 275190 & 319524 & 330964 \\
\hline
\end{tabular}

${ }^{\star}$ Medical subject heading absent in this year

total number of papers indexed in Medline each year increased by $189 \%$ between 1966 and 1990. Sixteen of the categories showed an increase in number of papers from 1960 to 1990 and in 11 of these categories the increase was by over $200 \%$. In 1966 there was a total of 12536 papers which could be relevant to a histopathologist and in 1990 this figure was 36780 (an increase of $293 \%$ ).

\section{Discussion}

Most of the categories examined showed an increase in the number of papers between 1966 and 1990. The most dramatic increases occurred in categories which included newly introduced techniques such as needle biopsy (an increase from 409 papers in 1978 to 859 papers in 1990) and immunohistochemistry (an increase from three papers in 1982 to 4058 papers in 1990). These increases reflect burgeoning interest in the application and development of new techniques in histopathology and a histopathologist would need to read many of these papers to assess the relevance of these techniques to their own practice. In only two categories did the number of papers decline during the study period. The number of papers under the medical subject heading of "cytodiagnosis" (E1.223.230) declined by $23 \%$ between 1966 and 1990 . Some of the first descriptions of diagnostic cytology were published in the 1840s and Papanicolaou's report on exfoliative cervical cytology appeared in $1928^{7}$ so much of the publications on cytodiagnosis may have been published before 1966 . The number of papers under the medical subject heading of "microscopy, polarisation" (E5.595.624) also declined but the number of papers in this category was small.

The total number of papers in 1990 which could be relevant to a histopathologist was $293 \%$ higher than that in 1966 . This is much greater than the increase in the total number of papers indexed (189\%), suggesting that the expansion in histopathology literature has been greater than in other medical subjects. This number may be a considerable underestimate of the total histopathology publications because Medline is estimated to contain only $40 \%$ of the world medical literature. ${ }^{89}$ Clearly no histopathologist could assimilate this volume of literature and various strategies have been suggested to deal with this problem. A more rigorous system of peer review could reduce the number of papers published but the amount of data being produced is increasing so worthwhile investigations could remain unpublished if this strategy were implemented. ${ }^{10}$ Informative abstracts and the use of "terse literature" can reduce the number of characters which need to be read, ${ }^{2}$ and specialisation within histopathology may limit the range of literature to be surveyed. The use of computer based retrieval systems can reduce the time spent monitoring the lists of journal contents for relevant articles.

We thank David Roberts of the British Library Document Supply Centre for his advice on medical subject heading indexing.

1 de Solla Price DJ. Science since Babylon. New Haven: Yale University Press, 1961

2 Kent A, Lancour H, Daily JE. Encyclopedia of library and information science. New York: Dekker, 1980:312-3.

3 de Solla Price DJ. The scientific foundations of science policy. Nature 1965;206:233-8.

4 Miller JDR, Starr L. Information explosion in radiology. $\underset{f}{ }$ Can Assoc Radiol 1988;39:33-6.

5 Pentelow GM. New technology in medical libraries. Br Med f 1989;298:907-8.

$f$ 1989;298:907-8.
Medical subject headings. Index Medicus. Bethesda: National Institutes of Health, 1991:32(Suppl).

7 Coleman DV, Evans DMD. Biopsy pathology and cytology of the cervix. London: Chapman and Hall Medical, 1988:2-3.

8 Roberts D. Information data bases. Lancet 1990;335:917.

9 Roberts D. Physiotherapy exercises and back pain. Br Med f 1991;303:314.

10 Abrams M. Publish or perish and peer review. Hcalth Trends 1989;21:65. 